\title{
Dietary Supplementation of Chicory Root Powder as Prebiotic Source to Augment Health of Murrah Buffalo Calves
}

\author{
Anjali Khare $^{1^{*} \text {, Veena Mani }}{ }^{1}$, Sachin Kumar ${ }^{1}$ and Gaurav Thorat ${ }^{2}$ \\ ${ }^{1}$ Animal Nutrition Division, ${ }^{2}$ Livestock Production Managment Division, ICAR-National \\ Dairy Research Institute, Karnal, Haryana, India \\ *Corresponding author
}

\section{A B S T R A C T}

Calf morbidity and mortality represent major financial losses for many dairy producers.

\section{Keywords}

Prebiotic, Calf,

Chicory root

powder, Body

length, $\mathrm{ADG}$

Article Info

Accepted:

20 June 2018

Available Online:

10 July 2018
The primary cause of calf mortality is diarrhea caused by intestinal bacterial infections. Traditionally, formulated antibiotics have been used as preventive treatments. However, as consumer concern about antibiotic resistance has increased, interest in alternative supplements has grown. Prebiotics are non-digestible food ingredients when taken sufficiently, selectively stimulate the growth and activity of one or a limited number of microbes in the gut that can improve the host health. In this trial twenty eight Murrah buffalo calves (7-10 d old and $31 \pm 2 \mathrm{~kg}$ ) were randomly selected and divided into four groups. All the four groups were fed as per ICAR (2013) feeding schedule except that these were additionally supplemented with $0,8,16$ and $24 \mathrm{~g} / \mathrm{d}$ chicory root powder (in the four respective groups i. e. $T_{0}, T_{1}, T_{2}, T_{3}$ ) for 90 days. Results showed that the ADG, total DMI, final body length and heart girth was significantly higher in treatment groups as compare to control. There is no significant difference observe in the wither height and hip height. Thus, it may be concluded that the supplementation of chicory root powder $(8,16$ and $24 \mathrm{~g}$ ) may be useful for enhancing health status and performance of calves.

\section{Introduction}

For several years antibiotics have been used as a growth promoter and also to obtain economic benefits in terms of improved calves performance and reduced calf mortality. However, the use of antibiotics in animal husbandry is in question because of antibiotic resistance of microorganisms. So the ban on the use of antibiotics as growth promoters in the European Union since January 1, 2006 (EC, 2001) urged the scientist to find a suitable alternative to antibiotics. To overcome these problems and to replace the use of antibiotics prebiotics came up as a good adjuvant to promote the health (Heinrich et al., 2003). Prebiotic supplementation has gained interest in recent years as a method to improve gastrointestinal health in livestock. It has been provided that prebiotic supplementation may be most effective in times of stress or increased pathogen exposure throughout the calf's lifetime (Quirk et al., 2010). Prebiotics are non-digestible food 
ingredients when taken sufficiently, selectively stimulate the growth and activity of one or a limited number of microbes in the gut that can improve the host health. The prebiotics mostly consist of dietary fibers and oligosaccharides. Inulin is one of the fructans, naturally occurring in many plants, mostly extracted from chicory root (Cichorium intybus) or Jerusalem artichoke (Helianthus tuberosus). Analysis of fresh roots of chicory gave water $77 \%$, gummy water $7.5 \%$, cellulose, inulin and fiber 9\% and ash $7.8 \%$ (Bais and Ravishankar, 2001). The root of the chicoryplant contains; $15-20 \%$ inulin and 5$10 \%$ oligofructose. andon dry basis it contains $50 \%$ inulin and $13 \%$ moisture. Chicory root is the dried and non-roasted root, Cichoriumintybus L used as a source of inulin, as soluble, fermentable fiber. Chicory also contain medicinally active substance like flavonoids, saponins, tannins, alkaloids, inulin, coumarins, sesquiterpene, lactones, vitamins, chlorophyll, pigments and unsaturated sterols (Atta et al., 2010). Chicory enhance the immunity and prevents inflammation and bacterial diseases due to presence of cichoricacid .Chicory has been traditionally used for the treatment of jaundice and gallstones fever and diarrhoea, (Abbasi and Farzanmeh, 2009). To keep all these factors in the mind the objective of this study to effect of chicory root on average daily gain and body growth measurement.

\section{Materials and Methods}

\section{Animal housing environment and dietary treatment}

Twenty eight Murrah buffalo calves (7-10 d old and $31 \pm 2.0 \mathrm{~kg}$ of body weight), were randomly assigned into four groups with seven animals in each group. All the calves were fed a similar which was nutritionally adequate diet as per the recommendations of ICAR (2013) feeding standards. T0 served as control while animals in Group II (T1), Group III (T2) and Group IV (T3) were supplemented with 8, 16, $24 \mathrm{~g}$ chicory root powder per calf/day respectively, given orally to individual calf . The total duration of experimental period was of 120 days. The feed intake was monitored on daily basis and body weight of the animals was recorded fortnightly.

\section{Housing and environment}

The study was conducted in the individual calf sheds of ICAR - National Dairy Research Institute Karnal, India. The calves were housed individually in well-ventilated pens.

\section{Feeding management}

The diet comprised of concentrate mixture (maize, bajra, GNC, SBM, MOC, wheat bran, rice polish, mineral mixture. bran, rice polish and mineral mixture. The animals were offered green fodder containing maize and jowar. All the calves had $24 \mathrm{hr}$ access to ad libitum clean water. The feeding of milk was carried out twice a day. Whole milk fed to the calves at 1/10th of actual BW up to 2 weeks, $1 / 15$ th of actual BW in the third and fourth week, 1/20th of actual BW in the fifth and sixth week, and $1 / 25$ th in the seventh and eighth week of study. Calf starter was offered from the second week onwards. All the calves were fed ad libitum concentrate mixture and green fodder (Ramaswamiet al., 2005).

\section{Experimental measurement}

Average daily gain (ADG) was calculated by subtracting the final body weight from the initial body weight and dividing it by the number of days. The feed intake and orts of the individual calf were recorded daily. The calves were offered measured amount of diet twice a day. After determining the dry matter (DM) content of feed offered and residue left, the mean dry matter intake (DMI) of each calf 
was calculated. Structural growth measurements, viz. body height, hip height and heart girth, were performed using "tape measures."

\section{Heart girth}

Heart girth was measured by taking the circumference around the chest just behind the scapula (Hump) with the help of measuring tape

\section{Body length}

Body length of the animal was measured from occipital joint to first caudal vertebra using a measuring tape.

\section{Wither height}

Wither height was measured from ground surface to point over the ridge between the shoulderwith measuring tape.

\section{Hip height}

Hip height was measured from ground surface to point over the hook bone with measuring tape.

\section{Statistical analysis}

The experimental data generated were analysed by ANOVA using the statistical software program SPSS (SPSS Inc., Chicago, Illinois, USA). Data on the were analysed using one-way ANOVA. The effects were considered to be significant at $\mathrm{p}<.05$.

\section{Results and Discussion}

\section{Dry matter intake}

The data on mean dry matter intake has been presented in Table 2. There is significant difference $(\mathrm{p}<0.05)$ in treatment and control.
Total dry matter intake was significantly ( $>0.05$ ) higher in T3 and similar in T2 and T1 lowest in T0.Results of the present study are in agreement with those of Ghoshand Mehla (2012) who also reported significantly higher mean total dry matter intake (696 vs. $649 \mathrm{~g}$ ) due to supplementation of $4 \mathrm{~g}$ prebiotic (MOS)/calf/day.

Similar effects have also been reported by other researchers (Uzmay et al., 2011; Silva et $a l ., 2012)$ in which MOS were supplemented to group of calves. Contradicting to our results Roodposhti and Dabiri (2012) observed that there was no significant difference in weekly dry matter intake (DMI) among treatments till the end of trial which was of 56 days.

\section{Average daily gain}

There is a significant $(\mathrm{p}<0.01)$ difference in average daily gainin treatment and control. However there is no siginifacnt differences observed in T1, T2 and T3 groups.

Overall average daily gain (ADG) was significantly $(\mathrm{P}<0.01)$ higher in $\mathrm{T} 3$ followed by $\mathrm{T} 2$ and $\mathrm{T} 1$ as compared to $\mathrm{T}$ showing no significant difference due to supplementation of 8 to $24 \mathrm{~g} / \mathrm{d}$ chicory root powder.

The better growth performance as observed in our study may be correlated to higher feed intake as well as better gut health in prebiotic fed groups . Similar to our findings, (Roodposhti and Dabiri, 2012) and (Krol., 2011) also observed consistently higher ADG in calves.

Contrary to our findings, (Morrison et al., 2010) and (Kara et al., 2015) reported no significant effect on body weight gain and feed conversion efficiency, though the values were higher numerically in groups supplemented with prebiotic in the form of MOS. 
Table.1 Growth performance, structural growth measurements and nutrient utilization of Murrah buffalo calves

\begin{tabular}{|c|c|c|c|c|c|c|}
\hline Parameter & $\mathrm{T}_{0}$ & $\mathrm{~T}_{1}(8 \mathrm{~g})$ & $\mathrm{T}_{2}(16 \mathrm{~g})$ & $\mathrm{T}_{3}(24 \mathrm{~g})$ & SEM & $\mathrm{P}$ value \\
\hline ADG (g) & $354.71^{\mathrm{a}} \pm 7.97$ & $389.62^{b} \pm 5.19$ & $399.79^{b} \pm 3.15$ & $400.68 \pm 10.01$ & 4.86 & $<0.001$ \\
\hline TDMI (g) & $1115.77^{\mathrm{a}} \pm 30.52$ & $1201.20^{\mathrm{ab}} \pm 29.78$ & $1212.45^{\mathrm{ab}} \pm 25.43$ & $1239.61^{b} \pm 23.44$ & 15.71 & 0.0233 \\
\hline \multicolumn{7}{|c|}{ Structural growth measurements $(\mathrm{cm})$} \\
\hline Body length Initial & $52.37 \pm 1.31$ & $53.32 \pm 0.92$ & $52.89 \pm 0.76$ & $52.25 \pm 0.51$ & 0.44 & 0.83 \\
\hline Final & $70.76^{\mathrm{a}} \pm 0.91$ & $73.46^{\mathrm{ab}} \pm 1.11$ & $76.20^{\mathrm{bc}} \pm 0.55$ & $77.65^{\mathrm{d}} \pm 0.58$ & 0.64 & $<0.001$ \\
\hline Heart girth Initial & $80.37 \pm 0.77$ & $81.48 \pm 0.72$ & $79.35 \pm 0.43$ & $80.31 \pm 0.82$ & 0.36 & 0.23 \\
\hline Final & $96.88^{\mathrm{a}} \pm 0.66$ & $100.22^{b} \pm 0.75$ & $97.43^{\mathrm{a}} \pm 0.46$ & $98.62^{\mathrm{ab}} \pm 0.93$ & 0.42 & 0.02 \\
\hline Wither height Initial & $69.22 \pm 0.65$ & $68.63 \pm 0.96$ & $69.54 \pm 1.47$ & $68.26 \pm 0.83$ & 0.98 & 0.814 \\
\hline Final & $84.25 \pm 0.46$ & $86.43 \pm 0.75$ & $86.43 \pm 2.55$ & $88.43 \pm 1.38$ & 1.54 & 0.308 \\
\hline Hip height Initial & $74.61 \pm 0.64$ & $74.12 \pm 1.35$ & $71.78 \pm 1.85$ & $72.24 \pm 0.78$ & 1.26 & 0.32 \\
\hline Final & $91.50 \pm 0.35$ & $92.86 \pm 0.99$ & $93.00 \pm 2.42$ & $92.86 \pm 1.16$ & 1.38 & 0.87 \\
\hline
\end{tabular}

Basal diet with no supplementation $\left(\mathrm{T}_{0}\right)$ or supplemented with chicory root powder $8 \mathrm{~g}\left(\mathrm{~T}_{1}\right), 16 \mathrm{~g}\left(\mathrm{~T}_{2}\right)$ and $24 \mathrm{~g}\left(\mathrm{~T}_{3}\right)$

${ }_{a, b, c}$ Means bearing different superscripts in a row $(a, b, c)$ differ significantly $(\mathrm{P}<0.05)$ 


\section{Body measument}

The results of body measurement have been presented in Table 2. It is depicted that initial body measurement was similar in all the groups. There is significant $(\mathrm{P}<0.05)$ difference observed in body length and heart girth. But there is no significant deferens observed in wither height and hip height Final body length $(\mathrm{cm})$ was significantly higher in T3 group and lower in T0group, The final heart girth $(\mathrm{cm})$ was highest in T1 group and lowest in T0 group. These results can be correlated to the changes observed in body weight in the study that was higher in supplemented groups. Calves receiving supplementation of prebiotic had higher average daily gain; hence structural growth measurements were better. There is highly significant correlation between body weight and linear measurements of calves (Gill and Hafs, 1971). In contrast, to our findings (Heinrichset al., 2003) reported no significant difference due to MOS supplementation in body measurements.

In conclusion, chicory root powder has potential for improving average daily gain, improving gut health fecal $\mathrm{pH}$, fecal microbiota and fecal metabolites of calves. So it could be conclude that $8 \mathrm{~g} / \mathrm{d}$ chicory root powder supplementation can reasonably be recommended for the calves for the overall health.

\section{References}

Abbasi, S. and Farzanmehr, H., 2009. Optimization of extracting conditions of inulin from Iranian artichoke with/without ultrasound using response surface methodology.JWSS.,13:423435.

Atta, N. F., El-Kady, M. F. and Galal, A. 2010. Simultaneous determination of catecholamines, uric acid and ascorbic acid at physiological levels using poly (N-methylpyrrole)/Pd-nanoclusters sensor.Anal.Biochem.,400:78-85.

Bais, H. P. and Ravishankar, G. A. 2001.Cichoriumintybus L-cultivation, processing, utility, value addition and biotechnology, with an emphasis on current status and future prospects. $J$. Food. SciAgri., 81:467-484.

Commission of the European Communities, Commission Recommendation. 2001. EC. Official J. European Union L., 161:42-44.

Ghosh, S. and Mehla, R. K. 2012. Influence of dietary supplementation of prebiotics (mannan- oligosaccharide) on the performance of crossbred calves. Trop. Anim. Health Pro., 44:617-622.

Gill, J. L. and Hafs, H. D. 1971.Analysis of repeated measurements of animals. J. Anim. Sc., 33: 331-336.

Heinrichs, A.J., Jones, C.M. and Heinrichs, B.S.2003. Effects of Mannan oligosaccharide or antibiotics in neonatal diets on health and growth of dairy calves. J. Dairy Sci., 86:40644069.

ICAR. 2013. Nutrient Requirements of Cattle and Buffaloes.3rd edn. Indian Council of Agriculture Research , New Delhi, India.

Kara, C., Cihan, H., Temizel, M., Catik, S., Meral, Y., Orman, A. and Gencoglu, H. 2015.Effects of Supplemental Mannan oligosaccharides on Growth Performance, Faecal Characteristics and Health in Dairy Calves. Asian Australas. J. Anim. Sci., 28: 1599-1608

Król, B. 2011. Effect of mannanoligosaccharides, inulin and yeast nucleotides added to calf milk replacers on rumen microflora, level of serum immunoglobulin and health condition of calves. Electronic. J. Polish Agric. Univ., Vol. 14 
Morrison, S.J., Dawson, S. and Carson, A.F. 2010.The effects of mannan oligosaccharide and Streptococcus faecium addition to milk replacer on calf health and performance. Livest. Sci., 131:292-296.

Quirk, G. J., Paré, D., Richardson, R., Herry, C., Monfils, M. H., Schiller, D. and Vicentic, A. (2010).Erasing fear memories with extinction training.J of Neurosci., 30:14993-14997.

Ramaswami, N., Chaudhary, L. C., Agarwal, N., and Kamra, D. N. 2005.Effect of lactic acid producing bacteria on the performance of male crossbred calves fed roughage based diet. AsianAustralas J. Anim. Sci., 18: 1110-1115.

Roodposhti, P.M. and Dabiri, N. 2012.Effects of Probiotic and Prebiotic on Average Daily Gain, Fecal Shedding of Escherichia Coli, and Immune System Status in Newborn Female Calves.Asian-Aust. J. Anim. Sci.,
25:1255 - 1261 .

Spring, P., Wenk, C., Dawson, K.A. and Newman, K.E. 2000.The effects of dietary mannan oligosaccharides on cecal parameters and the concentrations of enteric bacteria in the ceca of Salmonella-challenged broiler chicks. Poult. Sci.,79:205-211.

Uzmay, C., Kiliç, A., Kaya, I., Ozkul, H., Onenç, S.S. and Polat, M. 2011. Effect of mannan oligosaccharide addition to whole milk on growth and health of Holstein calves.Arch. Tierzucht., 54:127-136.

Silva, JackelineThaís da, Carla Maris Machado Bittar.and Lucas Silveira Ferreira 2012. Evaluation of mannanoligosaccharides offered in milk replacers or calf starters and their effect on performance and rumen development of dairy calves. $R$. Bras. Zootec., 13:746752.

\section{How to cite this article:}

Anjali Khare, Veena Mani, Sachin Kumar and Gaurav Thorat. 2018. Dietary Supplementation of Chicory Root Powder as Prebiotic Source to Augment Health of Murrah Buffalo Calves. Int.J.Curr.Microbiol.App.Sci. 7(07): 2999-3004. doi: https://doi.org/10.20546/ijcmas.2018.707.350 